\title{
Propuesta metodológica para el estudio de la viabilidad de la agricultura campesina y su testeo en dos granjas de Santiago del Estero (Argentina)
}

\author{
Methodological proposal to study the viability of the peasant farming and its testing in two \\ farms in Santiago del Estero (Argentina)
}

Ana Eliza Villalba ${ }^{1}$, Ramiro Rodriguez Sperat ${ }^{1}$, Maria Victoria Suárez ${ }^{1}$ ${ }^{1}$ Instituto de Estudios para el Desarrollo Social (Indes). Consejo Nacional de Investigaciones Científicas y Técnicas (Conicet) Universidad Nacional de Santiago del Estero (UNSE). Av. Belgrano Sur 1912, Santiago del Estero (Argentina). Código Postal: 4200.

Correo electrónico: ani.villalba89@gmail.com

\section{Resumen}

\begin{abstract}
Distintos autores expresaron dudas sobre la viabilidad de la producción campesina y su capacidad de subsistencia en el contexto capitalista actual. Sin embargo, la misma realidad brinda evidencias sobre su persistencia. Probablemente, su preconcepción como sector marginal, y condenado a desaparecer, ha generado ciertas dificultades para comprender su potencial y también ha contribuido a que, en la actualidad, y a pesar de los avances logrados en los últimos años, no exista un consenso sobre la viabilidad de la producción campesina, ni sea sencillo encontrar propuestas metodológicas para estudiarla. Este trabajo intenta adentrarse en la problemática y propone utilizar dos vertientes teóricometodológicas (la agroecología y los balances de la producción) que fueron complementadas entre sí y aplicadas en dos casos de estudio (ambos en Santiago del Estero, Argentina). Los resultados indican que la producción campesina puede ser viable, que es factible su constatación empírica y que esto puede realizarse mediante una herramienta fácilmente utilizable en terreno; sin embargo, para lograrlo es necesario partir desde otros indicadores que sean superadoras a los análisis estrictamente económicos.
\end{abstract}

Palabras clave: Producción agraria; agroecología; balances campesinos.

\begin{abstract}
Some authors expressed concerns about the viability of peasant production and its subsistence capacity in the current capitalist context. However, reality shows evidence of its persistence. Probably, its conception as a marginal sector, condemned to disappear, has made it difficult to understand its potential. Despite the progress made in recent years, there is no consensus about the viability of peasant production, and it is not easy to find methodological proposals to study it. This paper aims to immerse into the dilemma, using two theoretical and methodological frameworks of relevance (agroecology and production balances) that were complemented and applied in two case studies (both in Santiago del Estero, Argentina). The results indicate that peasant production may be viable, that its empirical finding is feasible, and that it can be easily usable in the field methods; however, in order to achieve this goals, it is necessary to take into account other indicators or forms of measurement, more comprehensive, than strictly economic analyzes.
\end{abstract}

Keywords: Agrarian production; agroecology; peasants balances.

Como citar: Villalba, A. E., Rodriguez-Sperat, R., \& Suárez, M. V. (2019). Propuesta metodológica para el estudio de la viabilidad de la agricultura campesina y su testeo en dos granjas de Santiago del Estero (Argentina). Acta Universitaria 29, e2135. doi. http://doi.org/10.15174.au.2019.2135 


\section{Introducción}

La mayoría de los estudios sobre el campesinado indican que una de las características distintivas de su producción es la configuración de una unidad económica familiar, donde el trabajo de sus propios miembros no suele ser asalariado y donde se conjuga la unidad de producción con la unidad doméstica (Chayanov, 1974; Llambí, 1989; Rodríguez-Sperat \& Jara, 2018).

Otro rasgo distintivo es su carácter parcialmente mercantil (Schejtman, 1980). Los productores campesinos utilizan los recursos que les ofrece la naturaleza para su producción, lo que actúa como un poderoso correctivo de la relación insumo-producto (Shanin, 1973), y pueden obtener buena parte de su ventaja competitiva por el uso que hacen de las relaciones sociales no mercantilizadas en las que se hallan inmersos (Smith, 1986). De esta forma, los procesos de no mercantilización constituyen una estrategia vital para disminuir su dependencia del sistema socio económico y ganar autonomía (Paz, Rodríguez-Sperat $\&$ González, 2009). Algunos autores definen a la producción campesina como una forma de producción no capitalista en la que, después de deducir los costos de producción, no es posible determinar la retribución respectiva de los factores: capital, trabajo, tierra; es decir, que no existen allí nociones equivalentes a la ganancia, el salario o la renta, por lo cual se sostiene que el trabajo campesino carece de valor monetario (Bartra, 1976).

Todos estos axiomas apuntan a una característica que resulta central en este tipo de explotaciones: "El productor campesino dispone de una estructura que le proporciona una gran flexibilidad para reducir al máximo la necesidad de uso del dinero y, si las circunstancias lo ameritan, es capaz de producir sin que intermedie él mismo durante el proceso productivo"1 (Van der Ploeg, 2006).

Estas particularidades se traducen en una gran dificultad al momento de pretender realizar estudios económicos sobre la producción campesina, ya que muchos de los elementos que comprenden este proceso de trabajo difícilmente pueden ser valorizados en dinero ${ }^{2}$ (Rodríguez-Sperat \& Jara, 2018), y esto se ve reflejado en las conclusiones de los trabajos económicos clásicos que han estudiado a la economía campesina.

Es así como autores de gran influencia han planteado serias dudas sobre la capacidad de subsistencia de los campesinos (Boltvinik \& Archer-Mann, 2016), al tiempo que cuestionaron su viabilidad económica y subvaloraron su potencial productivo (Akram-Lodhi \& Kay, 2009; Bernstein, 2009). Estas miradas tuvieron un importante correlato en Latinoamérica a través de políticas de modernización para el campesinado, o clasificaciones de campesinos que eran considerados a priori viables o inviables con base a las características de su explotación; "mientras el grupo viable recibiría algún apoyo destinado a mejorar su capacidad productiva, el grupo "inviable" sería apto únicamente para programas sociales de alivio de la pobreza" (Kay, 2001).

En relación a la dificultad de realizar estudios económicos sobre la producción campesina, ya a principios del siglo pasado existieron autores que se enfrentaron ante esta problemática e intentaron desarrollar abordajes para el estudio de la economía campesina; estos aportes oscilaron entre una teoría específicamente desarrollada para estudiarla (Chayanov, Makarov, Mann \& Boeke) y una adaptación teórica

${ }^{1}$ En ese sentido, Shanin (1973) comenta que, en tiempos de crisis políticas, guerras, etc., las explotaciones campesinas fueron capaces de desplegar estas capacidades, llegando a extremos de casi una total independencia del contexto socio económico dominante. Por su parte, Paz (2008) sostiene que el campesino es una bacteria muy especial que, al igual que las bacterias anaeróbicas que pueden vivir sin oxígeno, aprendieron a sobrevivir en un medio sin capital y situaciones económicas adversas, donde normalmente las empresas capitalistas no pueden hacerlo.

${ }^{2} \mathrm{~A}$ la cual se le adicionan los inconvenientes no menores que genera la falta de registros contables y estadísticos que caracterizan al sector. 
o metodológica de la economía convencional para tratar algún tema campesino de forma puntual, como por ejemplo las fluctuaciones en rendimientos, el alto riesgo de la innovación, etcétera (Lipton, Joy In Firth).

Otros avances muy interesantes se desarrollaron en el campo de la agroecología, un área de conocimiento relativamente novedosa que en los últimos años ha introducido herramientas de gran utilidad para los estudios campesinos (Altieri \& Nicholls, 2007; Sarandón et al., 2006; Sevilla-Guzmán, 2011; Toledo, 2002). Sin embargo, como se verá más adelante, debido a las preocupaciones que en su momento dieron origen a este tipo de estudios, los abordajes concentraron sus esfuerzos en resaltar sobre todo la importancia de las dimensiones ecológica y social en pro de equilibrarlas con -o anteponerlas a- un objetivo económico, y si bien se preocupan por no desconocer la importancia de esta última dimensión, muchas veces se da por sentado su consecución o se seleccionan indicadores que la dejan indirectamente en un segundo plano.

Claro ejemplo de esto es que la mayoría de los estudios pierden de vista aspectos que resultan fundamentales para la viabilidad de explotaciones campesinas actuales, por ejemplo, aquellos vinculados con la forma en la que se relacionan con los mercados o a cuestiones inherentes a su estrategia productiva (Van der Ploeg, 2015).

Con base en lo expuesto, este artículo tiene por objetivo proponer una metodología para el estudio de la viabilidad de la producción campesina, basada en abordajes técnico-procedimentales provenientes de la agroecología y complementada con adecuaciones teóricas propias de los estudios sobre la economía campesina, de forma tal que esta sea capaz de captar las características económicas, productivas y comerciales que tornan viable a este tipo de explotación, prestando especial atención a que los indicadores y variables utilizados puedan ser fácilmente relevados en terrero y aplicados a casos de estudio concretos.

Para ello, se propuso desarrollar el trabajo de la siguiente manera: En primer lugar, se discutieron las implicancias teóricas de la agroecología y sus vinculaciones con la viabilidad de la producción campesina; en una segunda instancia, se profundizó en los aspectos metodológicos donde se justifican las decisiones tomadas al respecto; y, finalmente, se aplicó la herramienta propuesta en dos estudios de caso de explotaciones campesinas y se expusieron los resultados obtenidos.

La hipótesis subyacente de esta investigación es que es posible demostrar empíricamente la viabilidad de la producción campesina y que ello puede ser realizado mediante una herramienta sencilla de utilizar en terreno. Pero para lograrlo es necesario utilizar otros indicadores o formas de medición que sean superadoras a los análisis estrictamente económicos. Es aquí donde la agroecología abre puertas muy interesantes de explorar.

\section{Sobre la agroecología y la viabilidad de la producción campesina}

Previamente a las discusiones metodológicas para estudiar los casos, resulta necesario establecer algunas pautas conceptuales con relación a los orígenes de la agroecología como disciplina y reflexionar sobre los desafíos que enfrenta la producción campesina para ser viable en la actualidad.

Como primera medida, es importante resaltar que existen distintas escuelas de pensamiento dentro de la agroecología ${ }^{3}$ (Altieri \& Nicholls, 2007); consecuentemente, no resulta una tarea sencilla encontrar

\footnotetext{
${ }^{3}$ Para el lector interesado en profundizar sobre las distintas escuelas de pensamiento en la corriente agroecológica, se recomienda la lectura de Altieri \& Nicholls (2007).
} 
una definición sintética y universal que las abarque a todas. Epistemológicamente, la agroecología integra los procesos naturales y sociales, uniendo disciplinas híbridas como la ecología política, la economía ecológica y la etnoecología, entre otras (Altieri \& Toledo, 2011).

Los trabajos que dieron cuerpo a esta vertiente teórica tuvieron su origen en la década de los setenta, en sintonía con importantes movilizaciones de protesta por parte de los movimientos ecologistas preocupados por los efectos del deterioro ambiental sobre el desarrollo humano derivados de la modernización capitalista (Sevilla-Guzmán, 2011) y distintos debates que se suscitaron en organismos multinacionales que planteaban el derecho de los seres humanos a un medio ambiente sano y el deber de protegerlo y mejorarlo para las futuras generaciones (Foladori \& Tommasino, 2000).

De hecho, es posible observar que una importante cantidad de trabajos sobre agroecología se adentran también en la discusión sobre el desarrollo sustentable (Altieri \& Nicholls, 2007), ya que desde sus orígenes comparten las mismas preocupaciones ecológicas y sociales ${ }^{4}$.

El axioma compartido es que el capitalismo, en su búsqueda del incremento constante de la productividad, el crecimiento económico ilimitado, la acumulación de riquezas y la explotación sin límites de los recursos naturales (y su consecuente degradación) terminaron por colocar la variable ambiental y la social por debajo de la variable económica, e incluso detrás de la categoría misma del desarrollo (SevillaGuzmán, 2011).

En lo que respecta al ámbito rural, el enemigo a vencer era el agronegocio, que producía una degradación ecológica y social sin contemplaciones en pos de alcanzar una renta económica cada vez mayor. A la vez, la necesidad de encontrar alternativas de producción más sustentables llevó a algunos autores a identificar en las producciones campesinas e indígenas sistemas que naturalmente cumplían con gran parte de los principios agroecológicos; consecuentemente, para dichos autores, esta forma de producción debería ser rescatada, sacada de la pobreza y transformada en una actividad sustentable y productiva (Altieri \& Nicholls, 2000), y la ciencia debería aprender de ella 5 (Sevilla-Guzmán, 2011).

En términos metodológicos, los abordajes planteados por la agroecología procuraron analizar con una mayor integralidad los sistemas agropecuarios, buscando que los mismos sean sustentables e identificando tres dimensiones que deben ser balanceadas para cumplir con este objetivo: la dimensión ecológica, la social y la económica (Altieri \& Nicholls, 2000; Sarandón \& Flores, 2014).

No obstante, y a pesar de que una buena parte de la literatura especializada en la temática haya identificado a la producción campesina como una producción, en principio, agroecológicamente sustentable y necesaria de rescatar, se observa que gran parte de los valiosos aportes de esta disciplina contienen en su interior un pecado original, que radica en que si bien los abordajes buscan una equiparación entre las dimensiones ecológica, social y económica, existe una presuposición implícita de que las dos primeras dimensiones normalmente se encuentran en inferioridad de condiciones que la

\footnotetext{
${ }^{4}$ Foladori \& Tommasino (2000) hacen un interesante agrupamiento para resumir las distintas posturas de los diferentes autores en torno al desarrollo sustentable y las clasifica en: aquellos para quienes la sustentabilidad es exclusivamente ecológica; aquellos para quienes la sustentabilidad es ecológica y social, pero donde la parte social es un vehículo para llegar a la sustentabilidad ecológica (sustentabilidad social limitada); y aquellos para quienes la sustentabilidad debe ser realmente social y ecológica en forma de coevolución (coevolución sociedadnaturaleza). "Como puede apreciarse, en los tres ejes o grupos hay dos elementos en juego: la sustentabilidad ecológica y la sustentabilidad social” (Foladori \& Tommasino, 2000)

5 "La agroecología critica el pensamiento científico: por un lado, desvelando el etnocentrismo sociocultural de las ciencias sociales como construcción histórica europea que centra su pesquisa en una única propuesta civilizatoria que excluye de su acervo conceptual a las demás. Y, por otro lado, pretendiendo modificarlo probando además la necesidad de complementar los hallazgos científicos agropecuarios y forestales con aquellas "prácticas campesinas e indígenas” que han mostrado su sustentabilidad histórica” (Sevilla-Guzmán, 2011).
} 
tercera (situación que en las explotaciones campesinas generalmente sucede al revés), y esto, desde nuestra perspectiva, deriva en que aún no se haya llegado a profundizar en ciertos elementos que para muchos autores especializados en economía campesina resultan determinantes para la viabilidad de una explotación campesina.

El trabajo de Van der Ploeg (2015) tal vez sea uno de los que explica estos elementos de manera más sintética y holística y los expresa mediante cinco balances que el productor campesino debe cuidar de mantener equilibrados:

- $\quad$ El balance entre el hombre y la naturaleza viva. Este balance implica básicamente que el sistema debe cumplir con el objetivo de proveer una producción suficiente, que permita al productor vivir de la tierra, pero que al mismo tiempo garantice la reproducción de la naturaleza, preferiblemente enriqueciéndola, mejorándola y diversificándola.

- El balance entre la producción y la reproducción. Las actividades de la granja no solo tienen que estar orientadas a la producción, sino también en la misma medida a la reproducción, y no solo de la naturaleza viva, sino de todos los elementos y recursos que hacen funcionar a la granja de forma aceitada.

- El balance entre los recursos internos y externos. De forma paralela a los recursos que son producidos y reproducidos de forma endógena (recursos internos), toda granja, donde sea que esté localizada, necesita de recursos externos a ella. Sin embargo, la naturaleza de esos recursos, su origen y, especialmente, la forma en la que ellos son adquiridos y los efectos del método de adquisición, pueden traer al productor consecuencias importantes. Este balance implica la necesidad de definir y construir continuamente un equilibrio entre los recursos internos y externos. Si los campesinos apoyan su producción en recursos externos, pueden lograr que el proceso productivo sea menos pesado, pero la granja será altamente dependiente de los mercados (pudiendo potencialmente ser devorada por los mismos). Alcanzar un balance adecuado ayuda a crear una autonomía relativa: una posición que permita que los estilos de producción se adapten a los intereses y perspectivas de las familias campesinas.

- $\quad$ El balance entre la autonomía y la dependencia. Este balance presta atención a dos aristas. Por un lado, desde una perspectiva macro, se toma en cuenta la incidencia del capital y las instituciones externas sobre la granja, en el sentido de detectar si ellas gradualmente van tomando el control sobre el proceso productivo y las decisiones de la familia. Por otro lado, la segunda arista guarda relación con el tercer balance y analiza si el productor, como consecuencia de lo anterior, tiene la suficiente libertad para diseñar sus estrategias de manera adecuada para a los intereses y perspectivas de la familia.

- $\quad$ El balance entre la escala y la intensidad. La escala se refiere al número de objetos de trabajo (unidades de tierra, animales, etc.) por unidad de fuerza de trabajo. La intensidad se refiere a la producción por objeto de trabajo (rinde por hectárea, litros de leche por animal, etc.). Existen dos formas contrastantes de incrementar los ingresos en la agricultura: aumentar la escala o la intensidad (e infinitas combinaciones intermedias entre ambos extremos). El comportamiento a lo largo de estos dos ejes determina un estilo de producción. Este estilo no es estático, va cambiando de acuerdo a las necesidades, intereses y perspectivas de las familias y también de acuerdo al contexto donde la granja se desempeña. En síntesis, este balance implica estudiar si existe una apropiada relación entre el estilo de producción que determina la escala e intensidad de la explotación y su comportamiento en relación con resto de los balances. 
- $\quad$ Para el autor, estos cinco balances permiten identificar los principales desafíos y oportunidades que el campesinado enfrenta en la actualidad y explican en cierta medida la considerable heterogeneidad que existe, tanto entre los diferentes países y regiones como hacia el interior de ellos mismos.

\section{Materiales y Métodos}

Sarandón \& Flores (2014) desarrollaron una propuesta para abordar los agroecosistemas que se caracteriza por su "sencillez, bajo costo y por su capacidad de evaluar aquellos aspectos que comprometen el logro de la sustentabilidad de los sistemas agrícolas" (Sarandon \& Flores, 2009), siendo esta una de las referentes en el campo de la agroecología actual ${ }^{6}$. Esta metodología fue complementada con los balances de Van der Ploeg (2015), intentando arribar a una propuesta de abordaje que pueda ser utilizada para el análisis de la viabilidad productiva de las explotaciones campesinas?

El desarrollo de la misma comienza con la siguiente definición: se entiende como agroecosistema campesino viable a aquel sistema ecológicamente sustentable, económicamente sostenible, socialmente aceptable y con una producción relativamente autónoma, que es llevado adelante con el objetivo de que los bienes y servicios que se extraen de este satisfagan las necesidades de los productores y contribuyan a su desarrollo, tanto personal como de la explotación, la comunidad y la región. Por otro lado, que a través de este sistema, el manejo y uso de los recursos naturales y demás factores productivos no accione en detrimento del ambiente, comprometiendo la disponibilidad de los mismos. Finalmente, que la estrategia productiva inmersa en un determinado contexto permita al productor mantener una relativa autonomía tanto con el mercado como con los recursos que emplea.

\section{Definición de las dimensiones de análisis}

Las dimensiones por considerar provienen de la definición de agroecosistema campesino viable detallada previamente, cuya base fue tomada de los trabajos sobre agroecología y aggiornada con base a los balances detallados en la sección anterior. Estas son:

- Dimensión ecológica

- Dimensión económica

- Dimensión sociocultural

- $\quad$ Dimensión de mercado

- Dimensión estrategia productiva

\footnotetext{
${ }^{6}$ A pesar de haber seleccionado esta metodología, no se desconocen otros aportes metodológicos como ser el de Masera, Astier \& López-Riadura (2000).

${ }^{7}$ Cabe destacar que esta propuesta de análisis se centra en un recorte de tiempo correspondiente a un momento especifico en la historia de la familia, con lo cual no contempla al conjunto de elecciones posibles que tiene el campesino en función a los recursos o capital de los que dispone, ni tampoco cómo estas elecciones cambian con el tiempo. También se destaca que se trata de sistemas en los que las dimensiones están profundamente relacionadas unas con otras, de modo que al modificarse una, modifica las restantes. Sin embargo, a los fines prácticos, se optó por este enfoque a pesar de sus limitaciones por su simpleza, comprendiendo que permite realizar a futuro nuevamente el estudio y observar cómo evolucionan las variables en el tiempo, y además puede ser complementado con herramientas cualitativas que permitan subsanar los aspectos aquí mencionados.
} 


\section{Construcción de indicadores}

Un indicador es algo que hace claramente perceptible una tendencia o un fenómeno que no es inmediatamente ni fácilmente detectable y que debe permitir comprender, sin ambigüedades, el estado de la viabilidad de un agroecosistema o los puntos críticos que lo ponen en peligro (Sarandón \& Flores, 2009).

Se diseñaron indicadores de performance (Altieri \& Nicholls, 2000) para evaluar el comportamiento de las explotaciones en cada una de las dimensiones analizadas. Para ello, se acudió a otros autores considerados referentes en cada una de las temáticas abordadas. Cabe destacar que ellos no son indicadores universales, sino construidos para el objetivo y la situación propuesta.

\section{Estandarización y ponderación de los indicadores}

Para facilitar el análisis de las dimensiones, siguiendo el criterio de Diotto, et al. (2014), los datos fueron relevados a través de indicadores estandarizados y transformados en una escala de 0 a 3 , independientemente de sus unidades, siendo indicadores directos, es decir, a mayor valor, mayor viabilidad. De esta manera, se integran varios indicadores de distinta naturaleza y unidad de medición a indicadores más sintéticos. Los indicadores se construyeron teniendo en cuenta las características de la producción campesina en general.

Luego se realizó la ponderación de cada indicador, multiplicándolo por un coeficiente según la importancia relativa o peso respecto al criterio de viabilidad adoptado.

En función a esto, si los resultados del análisis arrojan un valor promedio de entre 0 y 1 , se considera que se está frente a una explotación inviable; si se encuentran entre el 1 y 2 serán considerados en transición hacia la viabilidad; y entre 2 y 3 son explotaciones viables. Cabe destacar que entre estos valores extremos existen puntos intermedios que dan cuenta de una mayor o menor presencia de puntos críticos para los sistemas productivos en cuestión. La misma metodología se utilizó para definir cada uno de los subindicadores que conforman el correspondiente indicador. Es importante mencionar que los subindicadores fueron construidos y adaptados a los casos de estudio en particular.

\section{Casos de estudio seleccionados}

Las fincas campesinas que se analizan en el presente artículo son los casos de la familia Gómez y la familia González, emplazadas en Villa Robles, Departamento Robles, y San Carlos, Departamento Banda, respectivamente, dentro de la provincia de Santiago del Estero, en el noroeste de la República Argentina.

Estos casos fueron seleccionados por poseer las siguientes características: 1) presentan rasgos característicos de la agricultura campesina tales como indivisibilidad de la unidad de producción con la unidad doméstica, utilización de la mano de obra familiar, ausencia de salarios, no mercantilización de la producción, entre otras; 2) han demostrado cierta sostenibilidad en el tiempo; 3) los resultados de la producción les permitieron avanzar en una reproducción ampliada de la explotación; 4) sus predios cuentan con una estructura y condiciones agroecológicas similares, ya que ambos están ubicados dentro del área de riego de la provincia; 5) son productores con los que los autores vienen trabajando desde hace algunos años en temáticas relacionadas a la comercialización, la producción y el desarrollo rural.

El primer caso, el predio de la familia Gómez, cuenta con aproximadamente 8 ha, todas ellas de muy buena aptitud para el cultivo. De la extensión total de la explotación, se cultivan aproximadamente 7.5 ha 
( 5 ha de alfalfa, 1.5 ha de maíz y 1 ha de cebada) y el resto se ocupa para la vivienda familiar, un galpón y la cría de animales.

La estructura familiar está compuesta por Don Ricardo (50 años), quien es el jefe de la explotación, su pareja Arminda (43 años), su hija Luciana (1 año), su madrastra doña Nora (58 años) y su sobrina Johana (6 años).

Don Ricardo interviene directamente tanto en el proceso productivo como en la gestión de la explotación. Las mujeres del hogar se ocupan de las tareas domésticas, el cuidado de la huerta familiar, la elaboración de dulces y escabeches caseros, y desempeñan un rol muy importante en la gestión de la explotación, ya que comparten la toma de decisiones e incluso proporcionan su mano de obra en ciertos procesos donde se necesita de una mayor artesanalidad (como la faena, limpieza y embolsado de los pollos, la limpieza de los corrales, etc.).

En determinadas ocasiones, la familia contrata a peones de la zona para que ayuden en tareas especificas en las diferentes producciones (siembras, cosechas, enfardado, pariciones, faenas y tareas de mantenimiento en general), pero siempre manteniendo una participación activa y sin delegar las tareas de gestión, pagándoles por las horas y/o el día trabajado.

La producción de la finca es muy diversificada, siendo las principales actividades el engorde de aves de corral, la venta de fardos de alfalfa y la cría y engorde de porcinos (producciones que se realizan durante todo el año y que están orientadas principalmente a la venta).

La familia ha logrado desarrollar un esquema comercial que combina distintos formatos: la venta directa en la explotación, la venta directa en ferias locales, el reparto a domicilio y la venta por internet (Facebook, WhatsApp). Para construir estos canales de comercialización fueron fundamentales las redes sociales desarrolladas hacia afuera de los límites del predio. De hecho, entre los puntos donde la familia coloca su producción es posible destacar a los vecinos y conocidos de la zona, técnicos y empleados de distintas instituciones públicas que trabajan con ellos, compañeros de trabajo de un pariente que trabaja en un sanatorio de la ciudad, antiguos clientes que tenía la explotación cuando el responsable de la unidad de producción era el padre de Ricardo, y la gente que llega al predio por otros asuntos.

Cabe destacar que don Ricardo y doña Nora participan activamente en eventos sociales, capacitaciones, etcétera, siendo Ricardo en la actualidad el presidente de una de las cooperativas que funcionan en la localidad donde se asienta su finca.

El segundo caso de estudio, la familia González, cuenta con un predio de 5 ha propias, que se encuentran cubiertas casi en su totalidad por verdeos de verano (maíz y sorgo), avena (verdeo de invierno) y alfalfa para el pastoreo de los animales. El resto del predio lo ocupan la casa familiar y las instalaciones para la actividad lechera y quesera caprina. El productor utiliza además una importante superficie de monte que pertenece a los campos colindantes, donde suelta diariamente a sus cabras para que se alimenten.

La producción de la finca se orienta principalmente a la actividad quesera caprina y a la elaboración de chacinados.

La estructura familiar está compuesta por don Francisco (de 65 años) y su esposa Ángela (de 68 años), quien actualmente está jubilada como maestra de escuela. El matrimonio tiene dos hijas, pero ellas ya no residen en el predio desde hace mucho tiempo y, consecuentemente, nunca integraron el esquema productivo de la explotación. 
Don Francisco interviene directamente tanto en el proceso productivo como en el de gestión de la explotación. Doña Ángela lleva el manejo de la casa y suele encargarse de la atención al público. Además de ellos dos, se contrata una persona de manera permanente para llevar adelante las tareas de la producción pecuaria en general. También se contratan a dos mujeres para realizar trabajos de higiene, desinfección, limpieza, tareas de ordeñe del tambo y apoyo en la elaboración de los principales productos (quesos y chacinados).

El sistema pecuario es diversificado y está compuesto por dos equinos, dos vacas y dos terneras, 109 cabras, tres reproductores caprinos, siete cerdas reproductoras y un porcino padrillo. La cantidad de cabritos, capones y lechones varían de acuerdo al proceso productivo. Además, posee aves de corral, unas cuantas colmenas ubicadas en el monte y algunos árboles frutales. La producción se orienta a la venta y una parte menor al autoconsumo.

El proceso de transformación de los productos pecuarios se desarrolla a partir de la conversión de leche a queso y de producción de carne (especialmente la proveniente de los cerdos) a chacinados o embutidos. Los porcinos que se sacrifican son criados con insumos provenientes de la propia explotación (suero, forrajes, granos, entre otros) y de compras externas (como soja o maíz). La producción de quesos es la actividad principal desempeñada en la explotación y se realiza diariamente durante todo el año de forma artesanal.

Durante la época de clases, el establecimiento recibe la visita de escolares donde los maestros aprovechan para comprar productos elaborados artesanalmente. Es esta una forma de dar a conocer los productos y atraer clientes, ya que, mientras los escolares desayunan, se ofrece una degustación de los productos a los adultos. Otros canales de comercialización están dados por los clientes permanentes a los cuales les lleva el queso a su domicilio, la venta a un local de delicatessen de renombre en la ciudad capital y un comprador extra local que distribuye el queso en distintos puntos del país.

\section{Descripción y ponderación de los indicadores elegidos}

Se consideraron los siguientes indicadores y subindicadores para los sistemas productivos analizados:

\section{Dimensión ecológica}

Para esta dimensión se tomó la definición de Diotto et al. (2014), que sostiene que un sistema será ecológicamente sustentable si conserva o mejora los recursos prediales (Diotto et al., 2014). A partir de dicha definición, se estableció lo siguiente:

A) Prácticas de conservación: observa la conservación de la estructura y la vida del suelo. Ponderación $=1$.

Se toma esta ponderación partiendo de Diotto et al. (2014), quienes señalan que se considerará una mayor tendencia a la sustentabilidad del sistema cuando las prácticas de manejo realizadas colaboren con el mantenimiento de la estructura y la vida del suelo. Para ello, se consideraron los siguientes indicadores y sus respectivos subindicadores:

A.1. Atención a las prácticas de conservación: un sistema productivo tendrá mayor tendencia a la sustentabilidad si realiza labranza conservacionista. Ponderación =1. Puntúa (0): ausencia de prácticas conservacionistas (laboreo vertical, carga animal excesiva y sobrepastoreo, entre otros); puntúa (1): utiliza al menos una práctica conservacionista en su producción, (rotaciones de cultivo periódicas); puntúa (2): 
utiliza diversas prácticas conservacionistas, pero podría incorporar más; puntúa (3): sistema productivo que se basa en prácticas de conservación.

B) Manejo de la Biodiversidad: existen estudios que sostienen que el manejo de la biodiversidad espacial y temporal conducirá a una mayor estabilidad del sistema productivo, brindando servicios ecológicos como control biológico de plagas, reciclado de nutrientes, conservación del suelo y del agua (Altieri \& Nicholls, 2000), contribuyendo de esta manera a su sustentabilidad. Ponderación $=2$.

B.1. Biodiversidad temporal: La rotación de los cultivos aumenta la biodiversidad del sistema en el tiempo, ya que conserva los nutrientes y la estructura del suelo. Ponderación = 1. Puntúa (0): no realiza rotaciones; puntúa (1): realiza rotación cada dos o más años de 1 sola especie; puntúa (2): realiza rotaciones anuales; puntúa (3): realiza rotaciones anuales con más de dos especies.

B.2. Biodiversidad espacial: Se define como aquella conformada por los distintos ambientes o ecosistemas presentes en el sistema productivo, ya sean sectores de cultivos o distintas formaciones de vegetación natural (monte, pastizales, etc.) (Diotto et al., 2014). Ponderación = 0.5. Puntúa (0): monocultivo; puntúa (1): uno o dos sectores limitados de diversificación de ambientes y especies; puntúa (2): diversificación de ambientes y especies, presencia de sectores de vegetación arbustiva autóctona sobre alambrados o corrales de ramas presentes en los lotes; puntúa (3): muy diversificado, presencia de diversos ambientes, lotes completos o franjas de vegetación autóctona (monte).

C) Riesgo de erosión: teniendo en cuenta que el suelo de la región estudiada cuenta con una estructura pobre debido al alto índice de salinidad y al bajo contenido de materia orgánica, existe un alto riesgo de erosión vinculado al tipo de riego utilizado (generalmente por inundación) (Angella, Prieto \& Soppe, 2001). Ponderación = 2 .

C.1. Sistema de riego. Ponderación $=1$. Puntúa (0): no riega o lo hace de forma ineficiente; puntúa (1): riega solo por inundación, pero de forma eficiente (curvas de nivel); puntúa (2): utiliza dos o más sistemas de riego; puntúa (3): riego por goteo.

D) Agua: para el cumplimiento de los ciclos biológicos de los seres vivos así como de otras tareas que permiten el funcionamiento de los sistemas agropecuarios (generación de energía, limpieza e higiene, etc.), se debe disponer de agua, en lo posible, apta para consumo humano, para producción animal y vegetal (Van der Ploeg, 2015). Ponderación = 1 .

D.1. Disponibilidad de agua para la producción: El sistema será más sustentable en la medida en que tenga mayor acceso a fuentes de agua. Ponderación =1. Puntúa (0): no dispone de fuentes de agua; puntúa (1): tiene acceso al agua, pero de mala calidad; puntúa (2): tiene acceso al agua de calidad, pero limitado temporariamente por alguna razón; puntúa (3): tiene acceso libre al agua y de buena calidad.

Indicador ecológico:

$$
\frac{1 . A 1+2\left(\frac{B 1+B 2}{2}\right)+2 . C 1+1 . D 1}{6}
$$

\section{Dimensión económica}


Las actividades de la granja no solo deben estar orientadas a la producción sino también, y en la misma medida, a la reproducción; y no solo de la naturaleza viva sino de todos los elementos y recursos que hacen funcionar a la granja de forma aceitada (Van der Ploeg, 2015). Con base a esta definición, se establecieron los siguientes indicadores para evaluar la dimensión económica:

A) Importancia de la producción predial para la familia: Ponderación = 1 .

A.1. Volúmenes de producción entre campañas: Para la reproducción de la explotación, los niveles de producción deben ser estables a crecientes; es decir, la continuación del proceso productivo durante el período analizado en, al menos, la misma escala que en el ciclo anterior (Llambí, 1989). Ponderación = 1. Puntúa (0): no repite la actividad productiva; puntúa (1): la repite en menor escala; puntúa (2): la repite en la misma escala; puntúa (3): amplía la escala.

A.2. Composición de los ingresos familiares: Si los ingresos familiares son prediales o extraprediales, determina la estrategia familiar y el grado de orientación productiva de la finca (Schneider, 2003). Ponderación = 2. Puntúa (0): ingresos exclusivamente extraprediales; puntúa (1): ingresos mayormente extraprediales; puntúa (2): ingresos mayormente prediales; puntúa (3): ingresos exclusivamente prediales.

B) Capacidad de reproducción de las actividades: Ponderación = 2 .

B.1. Ingresos vs. Egresos: El criterio mínimo de eficiencia en términos de ingresos vs. egresos para un productor campesino que busca maximizar sus ingresos vendría dado por el logro de un nivel de ingresos que le permita mantener sus niveles previos de consumo y reponer los medios de producción desgastados en el proceso productivo sin alterar su escala de producción (Llambí, 1989), es decir, si las actividades generan excedentes. Ponderación $=2$. Puntúa (0): la mayoría de las actividades no generan ingresos; puntúa (1): la mayoría de las actividades genera ingresos, pero no permiten cubrir los costos monetarios que insume la producción; puntúa (2): la mayoría de las actividades generan ingresos que solo alcanzan a cubrir los costos monetarios de producción; puntúa (3): la mayoría de las actividades generan excedentes monetarios.

B.2. Ingresos por cada integrante de la familia: En este indicador se consideran los ingresos al sistema familiar provenientes de la producción a nivel predial, incluido el autoconsumo y los ingresos extraprediales. El conjunto de ingresos mensuales se considera en función del número de miembros del sistema (Tommasino, 2006). Ponderación = 1. Puntúa (0): de $\$ 0$ a \$2 499 por persona; puntúa (1): de $\$ 2500$ a \$4 999 por persona; puntúa (2): de \$5 000 a \$7 499 por persona; puntúa (3): más de \$7 500 por persona ${ }^{8}$.

Indicador económico:

$\frac{1\left(\frac{(A 1+2 \cdot A 2)}{3}\right)+2 \frac{2 \cdot B 1+B 2}{3}}{3}$

\section{Dimensión de Mercado:}

Uno de los grandes interrogantes que existe en los estudios económicos campesinos gira en torno a la conveniencia de orientar la producción campesina hacia el mercado, en el sentido de si este proceso puede

${ }^{8}$ Teniendo en cuenta los precios de la canasta básica dentro de la República Argentina para el año en el que se realizó el estudio (2016). 
traer aparejado la destrucción de la autonomía de la explotación, debido a que el capital y las instituciones externas empiezan a penetrar en la granja y, gradualmente, van tomando el control sobre el proceso productivo y las decisiones (Paz et al., 2011). Esta discusión, enmarcada dentro de una temática más amplia como el avance del capitalismo en la sociedad, es conocida como "el debate sobre la mercantilización" (Long, Van der Ploeg, Curtin \& Box, 1986). La dimensión de mercado busca analizar el grado de orientación al mercado por parte del productor y al mismo tiempo el grado de dependencia de la finca respecto al mismo. Cabe destacar que en la actualidad existe consenso sobre la posibilidad de que el productor oriente su producción al mercado y no por eso necesariamente dependa de él (Long et al., 1986).

A) Alternativas de mercado: Ponderación $=2$.

A.1. Sistema de comercialización: Se considera deseable una mayor independencia del mercado (Long et al., 1986), por lo cual se valorará positivamente una estructura comercial orientada hacia los circuitos cortos de comercialización. Ponderación = 1. Puntúa (0): venta exclusivamente mediante intermediarios; puntúa (1): las ventas se realizan en mayor proporción mediante intermediario y en menor medida al consumidor final; puntúa (2): las ventas se realizan en mayor proporción al consumidor final y en algunos casos mediante intermediarios; puntúa (3): las ventas se realizan exclusivamente a consumidores finales.

A.2. Canales de comercialización: se considera una mayor tendencia a la autonomía de la finca al observarse mayor número de posibilidades de comercialización y su accesibilidad (Rodríguez-Sperat, Paz, Suarez \& Díaz, 2015). Ponderación = 2. Puntúa (0): un canal y poco accesible; puntúa (1): más de un canal y poco accesibles; puntúa (2): un canal de fácil acceso; puntúa (3): varios canales de fácil acceso.

A.3. Diversificación de productos: Se considera que un sistema será más tendiente a la autonomía en la medida que este disponga de un mayor número de actividades productivas (Rodríguez-Sperat et al., 2015). Ponderación = 1. Puntúa (0): una actividad productiva; puntúa (1): dos actividades productivas; puntúa (2): tres actividades productivas; puntúa (3): cuatro o más actividades productivas.

B) Orientación al mercado. Ponderación = 1

B.1. Objetivo de la producción: Una producción se considera menos dependiente del mercado en la medida que la misma esté más orientada al autoconsumo (Van der Ploeg, 2006). Ponderación = 0.5. Puntúa (0): orientación a la plusvalía; puntúa (1): orientación a la renta; puntúa (2): orientación hacia la supervivencia; puntúa (3): orientación hacia el autoabastecimiento.

B.2. Capacidad para determinar el precio de venta de sus productos: Un productor tomador de precios es en principio menos autónomo respecto al mercado que aquel que tiene capacidad para establecer sus propios precios (Van der Ploeg, 2015). Ponderación =2. Puntúa (0): el productor es tomador de precios en todos sus productos; puntúa (1): el productor es tomador de precios en la mayoría de sus productos; puntúa (2): el productor es capaz de negociar el precio de la mayoría de sus productos y fijar sus propios precios; puntúa (3): el productor establece los precios para toda su producción de forma relativamente autónoma. 
Indicador de mercado:

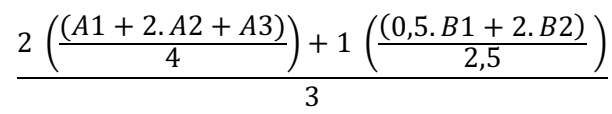

\section{Dimensión Sociocultural:}

La articulación con el contexto en el que tiene lugar la actividad socioproductiva tiene una gran importancia a la hora de evaluar sus posibilidades de reproducción social. Por lo tanto, resulta importante desarrollar instrumentos que permitan valorar la capacidad de negociación que tiene cada familia con los principales actores sociales con los que interactúan (por ejemplo, otros productores, agentes de comercialización, organizaciones, estado, etc.) (Cáceres, 2004).

A) Permanencia en la finca: La viabilidad se cumplirá en la medida en que el grupo familiar y los jóvenes permanezcan en la finca, promoviendo la continuidad de la unidad doméstica (Schneider, 2003). Ponderación $=2$

A.1. Existencia de un grupo familiar en la finca: La cantidad de personas que residan en la finca determinará la cantidad de mano de obra disponible y si las actividades productivas son capaces de cubrir las necesidades básicas del grupo familiar (Chayanov, 1974). Ponderación =1. Puntúa (0): reside solamente el productor/a; puntúa (1): reside el productor/a y su pareja; puntúa (2): residen pareja, hijos y/o personas a cargo; puntúa (3): existe más de un hogar en el lugar.

A.2. Permanencia de jóvenes y/o niños en la finca: Indagar sobre la cantidad de jóvenes que permanecen en la finca permitirá conocer la disponibilidad de mano de obra con la que cuenta la finca en caso de incrementar sus actividades productivas o, bien, si existe cierta posibilidad de continuar determinados emprendimientos ante la eventual ausencia de los miembros mayores de la familia (Tommasino, 2006). Ponderación = 2. Puntúa (0): no hay jóvenes ni niños en la finca; puntúa (1): presencia de jóvenes y/o niños de manera estacional (debido a que migran por estudios o trabajo); puntúa (2): jóvenes y/o niños que no viven en la finca pero que colaboran con determinadas actividades; puntúa (3): jóvenes y/o niños que viven en la finca de manera permanente.

B) Fortalecimiento de redes sociotécnicas: Comprende la posesión de una red duradera de relaciones de conocimiento mutuo. Es el conjunto de actividades, recursos, instituciones, relaciones, vínculos, niveles y redes que determinan las interconexiones entre distintos actores en un espacio rural determinado (Van der Ploeg, 2010) ${ }^{9}$. Ponderación $=1$.

B.1. Participación en organizaciones de distintos niveles: Se evaluará el grado y tipos de participación en organizaciones de la zona, tanto locales como provinciales, debido a que esto posibilitará un caudal de contactos y relacionamientos capaces de determinar si la unidad familiar se constituye como socialmente aceptable y consecuentemente viable en el tiempo. Ponderación = 1. Puntúa (0): no participa en ninguna organización; puntúa (1): participa ocasionalmente en alguna organización; puntúa (2): es un participante activo en organizaciones para las cuestiones de su comunidad; puntúa (3): forma parte del comité directivo o presidencia de alguna organización.

\footnotetext{
${ }^{9}$ Abordar la complejidad del concepto de fortalecimiento de redes sociotécnicas en su totalidad implicaría la realización de un trabajo de mayor amplitud y, teniendo en cuenta los alcances del trabajo, se decidió limitarse a tomar como parámetro las instancias de participación en organizaciones y los conocimientos adquiridos producto de dichas redes.
} 
B.2. Acceso a canales de educación formal o informal: Para los fines de este indicador, se considera deseable que la unidad familiar incorpore nuevas habilidades y conocimientos tanto productivos como organizacionales. El nivel de conocimiento de los campesinos condiciona sus capacidades de decisión, asignación de recursos, formas de relacionarse, el valor que este atribuye a su sistema productivo. Ponderación =1. Puntúa (0): no tiene estudios formales y tampoco recibe asistencia técnica de ningún tipo; puntúa (1): tiene estudios formales parciales pero no recibe asistencia técnica para su explotación; puntúa (2): tiene estudios formales parciales y recibe esporádicamente asistencia técnica por lo que no siempre incorpora nuevas habilidades; puntúa (3): tiene estudios formales parciales, recibe asistencia técnica asidua y accede a canales de información diversos que le permiten incorporar nuevos saberes a sus actividades productivas.

C) Satisfacción de necesidades básicas: En este indicador se consideraron componentes estructurales de las fincas que satisfacen algunas necesidades familiares y productivas (Tommasino, 2006). Ponderación = 1 .

C.1. Forma de tenencia de la propiedad: La seguridad jurídica en torno a la tenencia de la tierra tiende a promover la sostenibilidad del sistema en el largo plazo (de Dios, 2015). Ponderación = 0.5. Puntúa (0): tenencia precaria de la tierra; puntúa (1): ocupante físico o de hecho; puntúa (2): tenencia con título en trámite o, bien, heredada; puntúa (3): propietario con título.

C.2. Tipo de vivienda en la cual habitan: La casa expresa la voluntad de arraigo del hombre en el paisaje y revela la capacidad de sus ocupantes para adaptarse a las condiciones de su ambiente natural, respondiendo a las exigencias de su género de vida, al tipo de tenencia de la tierra, a los recursos económicos de los que disponen, las circunstancias históricas, etc. (Cáceres, 2004). Ponderación =0.5. Puntúa (0): casa precaria y techo de adobe; puntúa (1): casa precaria con techo de chapa; puntúa (2): casa precaria de material con techo de chapa; puntúa (3): casa de material cemento y techo de chapa.

C.3. Existencia de luz eléctrica y agua potable en la vivienda: la existencia de energía eléctrica y agua potable no solo permite su aplicación para mejoras en la producción, sino también tener una condición de vida más digna y saludable (Cáceres, 2004). Ponderación = 0.5. Puntúa (0): no tiene luz eléctrica ni agua potable; puntúa (1): tiene luz eléctrica por algún medio de generación alternativo, pero no agua potable; puntúa (2): tiene luz eléctrica por red pública y no agua potable; puntúa (3): tiene luz eléctrica por tendido y agua potable por red pública.

C.4. Disponibilidad de hectáreas por el número de personas que habitan o producen en esa explotación: Disponer de una cantidad de tierra acorde a las necesidades de vida de la familia es uno de los reclamos históricos de todas las organizaciones campesinas. Khusro (1973) realizó un ejercicio buscando estimar el tamaño de la granja bajo el cual la producción es demasiado pequeña como para mantener una familia. El tamaño resultante fue de 15 acres (1,5 ha). A mayor superficie disponible, mayores serán las posibilidades de ampliar la producción y diversificarla. Ponderación $=2$. Puntúa (0): menos de 0.75 ha por persona; puntúa (1): entre 0.75 ha y 1.5 ha por persona; puntúa (2): entre 1.5 ha y 2.25 ha por persona; puntúa (3): más de 2.25 ha por persona.

Indicador sociocultural:

$\frac{2\left(\frac{A 1+2 \cdot A 2}{3}\right)+1\left(\frac{B 1+B 2}{2}\right)+1\left(\frac{0,5 \cdot C 1+0,5 \cdot C 2+0,5 \cdot C 3+2 \cdot C 4}{3,5}\right)}{4}$




\section{Dimensión estrategia productiva}

Toda granja, donde sea que esté localizada, necesita de recursos externos a la misma de forma paralela a los recursos que produce y reproduce de forma endógena (recursos internos). Sin embargo, la naturaleza de esos recursos, su origen y, especialmente, la forma en la que ellos son adquiridos y los efectos del método de adquisición pueden traer al productor consecuencias importantes (Van der Ploeg, 2015).

\section{A) Autonomía de la producción: Ponderación = 1}

A.1. Grado de mercantilización: Si los insumos que se utilizan en el proceso productivo son obtenidos a través de sus respectivos mercados o son producidos, reproducidos o intercambiados en circuitos no mercantiles (Van der Ploeg, 2010). Ponderación = 2. Puntúa (0): la fuerza de trabajo y los demás recursos entran en el proceso como mercaderías, y todos los productos obtenidos circulan también como tales; puntúa (1): la mayoría de los recursos materiales, sociales y fuerza de trabajo entran en el proceso de trabajo como mercaderías, y la producción es comercializada en su totalidad; puntúa (2): la mayor parte de la producción es comercializada, y la mayoría de los recursos materiales y sociales entran en el proceso de trabajo como mercaderías, pero la fuerza de trabajo es íntegramente familiar o en una gran proporción (al menos un 75\%); puntúa (3): la producción es comercializada al menos en parte, pero ni la fuerza de trabajo ni otros recursos cruciales (tierra, agua, semillas, animales, conocimiento, redes de trabajo, etc.) entran en el proceso de trabajo como mercaderías.

A.2. Dependencia de las Redes Sociales: La agricultura campesina logra buena parte de su ventaja competitiva por el uso que hace de las relaciones sociales no mercantilizadas en las que se halla inmersa (Smith, 1986). Este subindicador analiza el grado de dependencia respecto a las vinculaciones establecidas con agentes externos para la producción. Ponderación = 2. Puntúa (0): utiliza con asiduidad sus vínculos y contactos y depende de dichas relaciones para su producción; puntúa (1): utiliza sus vínculos y contactos ante situaciones productivas y/o comerciales puntuales, y son muy importantes en su producción; puntúa (2): utiliza esporádicamente sus vínculos y contactos para producir y/o para comercializar, pero no depende en gran medida de dichos contactos; puntúa (3): no necesita utilizar sus vínculos ni contactos para producir ni para comercializar.

A.3. Dependencia de las fuentes de financiamiento: presencia o no de préstamos, subsidios, créditos, etc., y formas de devolución. Ponderación = 0.5. Puntúa (0): necesita financiarse para poder producir y solo lo puede hacer mediante préstamos con condiciones perjudiciales para la explotación; puntúa (1): necesita financiarse para poder producir, pero tiene acceso a algún sistema de financiamiento blando; puntúa (2): no necesita de financiamiento para su producción, pero accede si se le presenta alguna propuesta con condiciones muy favorables (crédito subsidiado, subsidio, etc.); puntúa (3): no necesita financiarse para producir o para avanzar con sus nuevos proyectos.

\section{B) Grado de externalización: Ponderación =1}

B.1. Endogeneidad de los recursos productivos: Si para producir utiliza recursos propios de la finca o externos (Van der Ploeg, 2010). Ponderación =1. Puntúa (0): todos los recursos productivos utilizados son externos al predio; puntúa (1): la mayor parte de los recursos son externos al predio; puntúa (2): solo una menor parte de los recursos son externos al predio; puntúa (3): la totalidad de los recursos provienen del mismo predio.

B.2. Composición de la mano de obra: composición de la mano de obra utilizada en el predio. Ponderación =1. Puntúa (0): mano de obra familiar insuficiente y sin posibilidades de contratar personal; puntúa (1): mano de obra familiar insuficiente, pero con posibilidades de contratar personal; puntúa (2): 
mano de obra familiar suficiente, pero la complementa con personal contratado; puntúa (3): mano de obra suficiente y exclusivamente familiar.

C) Estrategia para incrementar los ingresos. Existen dos formas contrastantes de incrementar los ingresos: aumentar la escala o la intensidad (e infinitas combinaciones intermedias) (Van der Ploeg, 2015). Ponderación = 1 .

C.1. Balance entre escala e intensidad: La escala se refiere al número de objetos de trabajo (unidades de tierra, animales, etc.) por unidad de fuerza de trabajo. La intensidad se refiere a la producción por objeto de trabajo (rendimiento por hectárea, litros de leche por animal, etc.). El comportamiento a lo largo de los dos ejes determina un estilo de producción, que debe ser acorde a las necesidades, intereses y perspectivas de la familia campesina. La agricultura campesina está caracterizada por intensificación lograda mediante el trabajo. Ponderación = 1. Puntúa (0): estilo de producción orientado a ahorrar trabajo (alta escala y baja intensidad); puntúa (1): estilo de producción a gran escala (alta escala y alta intensidad); puntúa (2): estilo de producción económico (baja escala y baja intensidad); puntúa (3): estilo de producción intensivo (baja escala y alta intensidad).

Indicador de estrategia productiva:

$$
\frac{1\left(\frac{2 . A 1+2 \cdot A 2+0,5 \cdot A 3}{4,5}\right)+1\left(\frac{B 1+B 2}{2}\right)+1\left(\frac{C 1}{1}\right)}{3}
$$

\section{Instrumentos de recolección de la información}

A partir de los indicadores descritos en el punto anterior, se diseñó una encuesta semiestructurada con preguntas abiertas y cerradas dirigidas a todos los integrantes de la familia que intervienen directamente en la producción. La información obtenida fue volcada en una matriz para permitir su posterior análisis.

Además, se complementó con el uso de planillas de seguimiento prediales, observación directa en terreno y entrevistas en profundidad con los distintos miembros de la familia.

Los datos fueron relevados durante los meses de junio a agosto del año 2016, para ambos productores.

\section{Resultados y Discusión}

A continuación, se exponen los resultados promedios obtenidos para cada una de las explotaciones y para cada dimensión en general (tabla 1).

Tabla 1. Valores obtenidos en cada una de las dimensiones de análisis y su promedio para cada una de las explotaciones.

\begin{tabular}{lccccc}
\hline & $\begin{array}{c}\text { Dimensión } \\
\text { Ecológica }\end{array}$ & $\begin{array}{c}\text { Dimensión } \\
\text { Económica }\end{array}$ & $\begin{array}{c}\text { Dimensión de } \\
\text { Mercado }\end{array}$ & $\begin{array}{c}\text { Dimensión Socio- } \\
\text { cultural }\end{array}$ & $\begin{array}{c}\text { Dimensión de } \\
\text { Estrategia productiva }\end{array}$ \\
\hline Familia Gomez & 1.17 & 2.56 & 2.53 & 2.65 & 2.27 \\
Familia Gonzalez & 1.00 & 2.78 & 2.80 & 1.17 & 2.24 \\
\hline
\end{tabular}

Fuente: Elaboración propia. 
Si se toman en cuenta solo los valores promedio, es posible sostener que ambas explotaciones constituyen agroecosistemas campesinos viables. Se arriba a dicha conjetura al observar el promedio general de todas las dimensiones involucradas en el análisis, tanto para la familia Gómez como para la familia González, ya que ambas arrojan valores próximos entre sí y superiores al 2, lo cual resulta relativamente elevado si se considera que, dentro de la escala establecida, el puntaje más alto posible lo representa el valor 3 (figura 1).

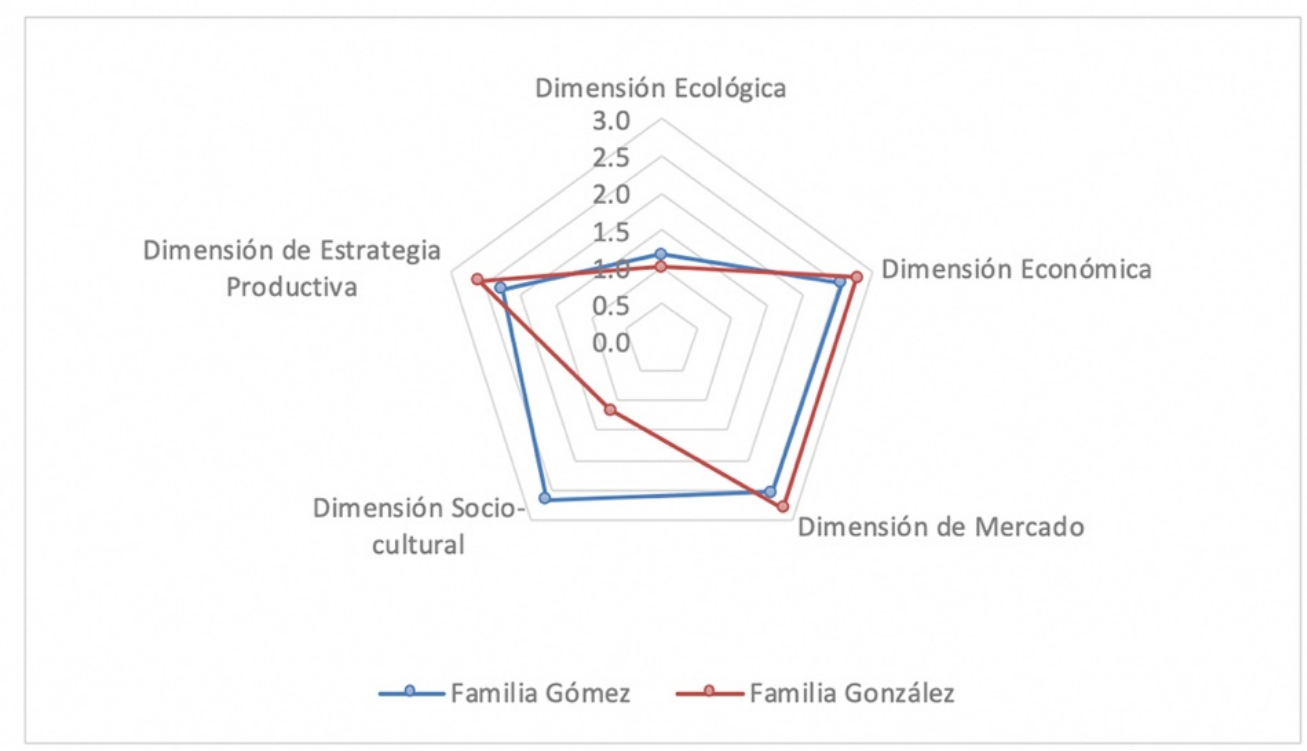

Figura 1. Valores promedio para cada una de las distintas dimensiones evaluadas en las explotaciones estudiadas. Fuente: Elaboración propia

Pero si, en cambio, se analizan los valores para cada una de las dimensiones en particular, el panorama comienza a modificarse. Para el caso de la familia Gómez, es posible observar que la Dimensión Ecológica representa la dimensión con el valor más crítico, mientras que para el caso de la familia González los valores más bajos se encuentran tanto en la Dimensión Sociocultural como en la Dimensión Ecológica.

Estas son áreas que deberían ser vigiladas y trabajadas de cerca por parte del productor, ya que a mediano plazo podrían condicionar la viabilidad de sus producciones y los recursos naturales prediales. Sin embargo, al observar el resto de las dimensiones, también es posible advertir que ambas familias despliegan una serie de mecanismos al interior de las unidades que, al operar en conjunto, no solo posibilitan la continuidad de la producción, sino que arrojan algunas pistas sobre cómo logran ser viables en su forma de vida campesina.

Lo precedentemente mencionado se puede observar con mayor detalle en la tabla 2. 
Tabla 2. Dimensiones, descriptores e indicadores evaluados en cada uno de los casos de estudio.

\begin{tabular}{|c|c|c|c|c|c|c|c|c|c|c|c|c|c|c|c|c|c|c|c|c|c|c|c|c|c|c|c|c|}
\hline \multirow{2}{*}{$\begin{array}{l}\text { Dimensión } \\
\text { Descriptor }\end{array}$} & \multirow[b]{2}{*}{$\mathrm{A}$} & \multicolumn{4}{|c|}{ Ecológica } & \multicolumn{4}{|c|}{ Económica } & \multicolumn{5}{|c|}{ De Mercado } & \multicolumn{9}{|c|}{ Socio-cultural } & \multicolumn{5}{|c|}{ Estrategia Productiva } \\
\hline & & 1 & & $\mathrm{C}$ & $\mathrm{D}$ & A & & B & & & A & & B & & $A$ & $A$ & $\mathrm{~B}$ & & & $\mathrm{C}$ & & & & A & & $\mathrm{B}$ & $B$ & C \\
\hline Indicador & 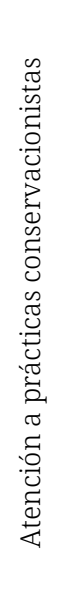 & 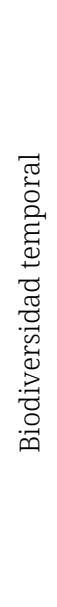 & 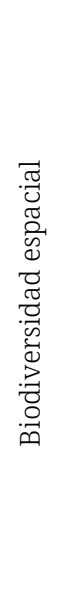 & 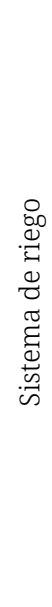 & 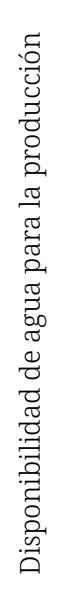 & 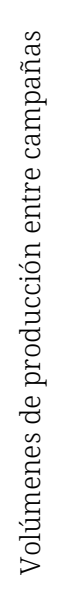 & 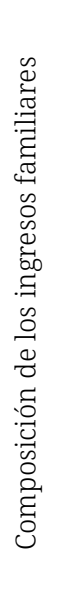 & 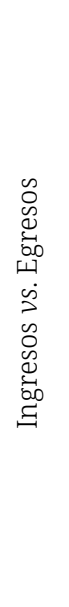 & 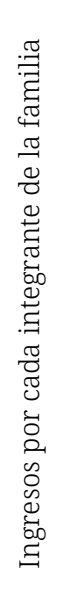 & 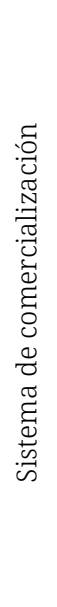 & 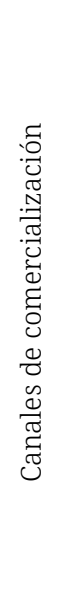 & 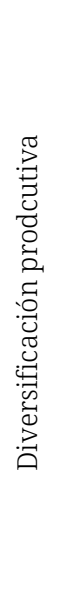 & 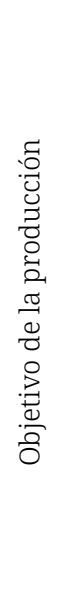 & 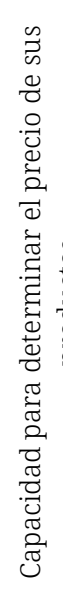 & 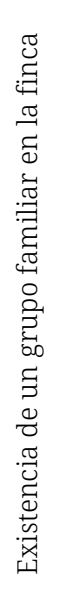 & 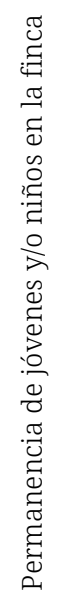 & 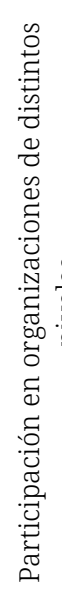 & 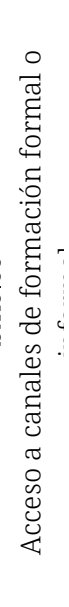 & 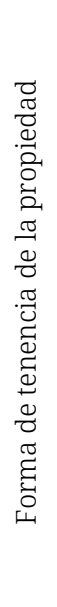 & 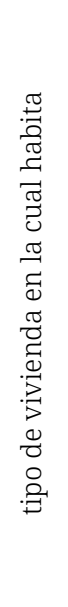 & 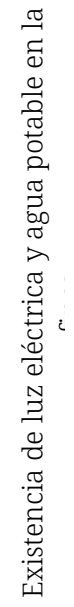 & 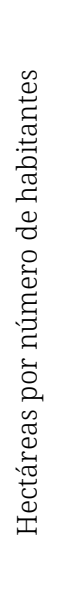 & 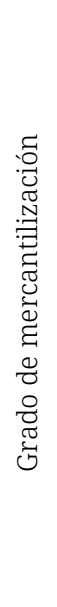 & 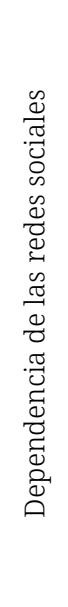 & 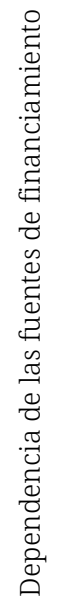 & 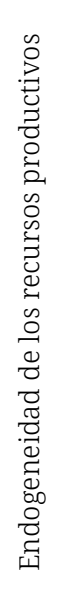 & 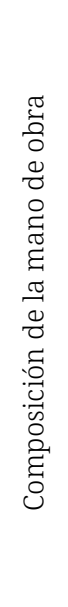 & 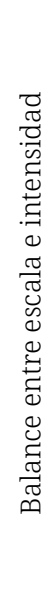 \\
\hline $\begin{array}{l}\text { Familia } \\
\text { Gómez }\end{array}$ & 1 & 1 & 2 & 0 & 3 & 3 & 2 & 3 & 2 & 2 & 3 & 3 & 1 & 2 & 2 & 3 & 3 & 3 & 2 & 3 & 3 & 2 & 2 & 1 & 2 & 1 & 2 & 3 \\
\hline $\begin{array}{l}\text { Familia } \\
\text { González }\end{array}$ & 1 & 1 & 2 & 0 & 2 & 3 & 2 & 3 & 3 & 2 & 3 & 3 & 1 & 3 & 1 & 0 & 0 & 2 & 3 & 3 & 3 & 3 & 2 & 3 & 3 & 2 & 1 & 3 \\
\hline
\end{tabular}

Fuente: Elaboración propia.

Hacia el interior de cada una de las dimensiones existen ciertos puntos críticos que deberían ser trabajados.

Es posible observar que la familia Gómez tiene como puntos críticos dentro de la Dimensión Ecológica la ausencia de prácticas de conservación y un sistema de riego por inundación que trae aparejado un importante riesgo de erosión para el suelo. Estos son dos aspectos a trabajar por parte del productor ya que representan un importante riesgo potencial para la sustentabilidad ecológica del predio en el mediano plazo. En lo relativo a la Dimensión Económica, todos los valores resultantes son muy altos. En la Dimensión de Mercado el valor más bajo se remite al importante grado de orientación al mercado que tiene la finca, pero este aspecto se complementa con una estrategia comercial diversificada desplegada por la familia con base a circuitos cortos de comercialización, por lo cual termina representando un riesgo menor para la autonomía de la explotación. La Dimensión Sociocultural también se presenta como una dimensión muy robusta para la familia, expresando altos valores en la gran mayoría de los indicadores. Finalmente, la Dimensión Estrategia Productiva tiene como punto crítico el grado de endogeneidad de los recursos productivos, pero al encontrarse balanceado con una mano de obra mayormente familiar y una estrategia para incrementar los ingresos basada en la baja escala y alta intensidad, no termina presentando efectos negativos para el sistema en su conjunto.

Al analizar los valores para la familia González, es posible encontrar los siguientes puntos críticos: En la Dimensión Ecológica además de la ausencia de prácticas conservacionistas y el riesgo de erosión por el sistema de riego utilizado, existe un tercer punto crítico que se vincula con la poca rotación de los cultivos que atenta contra la biodiversidad temporal del sistema. La Dimensión Económica y la de Mercado se 
muestran como esferas muy fuertes en esta explotación en particular, arrojando valores incluso superiores que los de la Familia Gómez. En lo que respecta a la Dimensión Sociocultural, existen dos puntos críticos que representan un importante riesgo a mediano plazo: la ausencia de jóvenes y/o niños en la finca que pone en riesgo su perdurabilidad en el tiempo y su poca participación en organizaciones de distintos niveles. Como último punto, en la Dimensión de Estrategia Productiva se observa como punto crítico la composición de la mano de obra, donde existe un importante peso de la mano de obra contratada en relación con la mano de obra familiar, pero al complementar este esquema laboral con una estrategia de endogeneidad de los recursos productivos utilizados y una estrategia de baja escala y alta intensidad para sus objetos de trabajo, el balance final en esta dimensión termina resultando positivo.

\section{Conclusiones}

De lo desarrollado hasta el momento, existen varias cuestiones que merecen ser resaltadas y analizadas con mayor detenimiento.

Como primera medida, se observa que las explotaciones campesinas estudiadas a priori constituyen agroecosistemas campesinos viables; de hecho, los valores promedio para la totalidad de las dimensiones analizadas así lo manifiestan. Sin embargo, al profundizar hacia el interior de cada una de las dimensiones, es posible observar que existen algunos puntos críticos que en el mediano/largo plazo constituyen un importante riesgo para ambas explotaciones.

La ausencia de prácticas conservacionistas y un sistema de riego que trae aparejado importantes riesgos de erosión por salinidad para el suelo son elementos críticos que comparten ambas explotaciones; sería recomendable que los productores trabajen sobre estos aspectos buscando equilibrar la dimensión ecológica con los buenos resultados obtenidos en el resto de las dimensiones. Además, la familia González, en particular, cuenta con otros puntos críticos en el plano sociocultural: El matrimonio ya es mayor de edad y al momento del estudio no contaba con jóvenes o niños en el predio que garantizaran la continuidad de la explotación, y no participa en organizaciones de distintos niveles, recortando de esta manera una red potencial de contactos que le proporciona tanto formación como acceso a determinados recursos.

En consecuencia, es posible sostener que los casos estudiados son representativos de agroecosistemas campesinos económicamente sostenibles, aceptables socialmente (en el caso de la Familia González esto puede llegar a ser discutido) y con una producción relativamente autónoma, la cual es llevada adelante con el objetivo de que los bienes y servicios que se extraen de ellos satisfagan las necesidades de los productores y contribuyan a su desarrollo, tanto personal como de la explotación, la comunidad y la región, donde la estrategia productiva, inmersa en este contexto en particular, permite a los productores mantener una relativa autonomía tanto con el mercado como con los recursos que emplea.

Sin embargo, no se podría sostener que estos agroecosistemas campesinos son ecológicamente sustentables, ya que, debido al manejo y el uso que hacen de los recursos naturales y demás factores productivos, terminan accionando en detrimento del medio ambiente, comprometiendo la disponibilidad de ellos.

Con relación a la metodología empleada, es posible destacar que la construcción y ajuste de los indicadores permitió una caracterización integral de los sistemas productivos, detectando puntos críticos en los que las explotaciones demuestran cierta fragilidad en su viabilidad a mediano/largo plazo. Por otra parte, esta metodología resulta de sencilla aplicación en terreno y apta para ser replicada en otros casos de 
estudio (con la salvedad de que los indicadores, subindicadores y descriptores deben ser adaptados a cada caso en particular).

Cabe destacar, que al momento de emplear una metodología similar se debe tener en cuenta que resultó dificultoso procesar aquellos índices que concentran información (concentran indicadores), entorpeciendo la diferenciación de condiciones variadas de viabilidad entre sistemas al agruparlos y tratar de hallar semejanzas dentro del grupo y diferencia entre grupos. Otra dificultad metodológica que requiere de claridad conceptual para su resolución se dio en la etapa de clasificar condiciones por dimensiones (a pesar de considerar las interacciones entre ellas, con efectos de una sobre otra).

Finalmente, en procura de realizar algunos aportes a la discusión sobre la viabilidad de la producción campesina, los resultados obtenidos en los casos estudiados darían cuenta de que este tipo de explotaciones pueden ser viables en su producción; sin embargo, sería necesaria una mayor cantidad de estudios en esta línea para poder confirmarlo. De corroborarse esta tendencia, la gran pregunta a responder pasaría a ser ¿Por qué hasta el momento la ciencia en general y los estudios económicos en particular no han sido capaces de detectarlo?

Por otro lado, teniendo en cuenta los valores que arrojan los casos estudiados en la dimensión ecológica, se abre el interrogante sobre si realmente es posible afirmar, tal como sostiene parte de la literatura agroecológica, que toda producción campesina naturalmente cumple con gran parte de los principios agroecológicos. Responder a esta pregunta excede a los objetivos de este artículo, y solo nos limitamos a dejarlo planteado como una posible línea de investigación para futuros trabajos.

Cabe señalar que se considera importante contemplar para posteriores trabajos, la importancia de contar con la participación de los campesinos en la elaboración, priorización y ponderación de los indicadores, a manera de lograr y co-construir un trabajo desde una visión más integral.

\section{Referencias}

Akram-Lodhi, A., \& Kay, C. (2009). Neo-liberal globalization, the traits of rural accumulation and rural politics: The agrarian question in the twenty-first century. En: A. H., Akram-Lodhi, \& C. Kay. (Eds.), Peasants and Globalization (pp.315338). Londres, Inglaterra: Routledge.

Altieri, M. A., \& Nicholls, C. I. (2000). Agroecología: teoría y práctica para una Agricultura Sustentable. Distrito Federal, México: Programa de las Naciones Unidas para el Medio Ambiente (Pnuma)-Red de Formación ambiental para América Latina y El Caribe.

Altieri, M. A., \& Nicholls, C. I. (2007). Conversión agroecológica de sistemas convencionales de producción: teoría, estrategias y evaluación. Ecosistemas. Revista científica de ecología y medio ambiente, 16(1), 3-12.

Altieri, M. A., \& Toledo, V. M. (2011). The agroecological revolution of Latin America: rescuing nature, ensuring food sovereignity and empowering peasants. The Journal of Peasant Studies, 38(3), 587-612. doi: https://doi.org/10.1080/03066150.2011.582947

Angella, G. A., Prieto, D. R., \& Soppe, R. (2001). Eficiencia de riego en el área de riego del río dulce, Santiago del Estero, Argentina. Campo para todos. 6(30), 25-27.

Bartra, R. (1976). Introducción a Chayanov. Nueva Antropología, 3(1),49-70.

Bernstein, H. (2009). Agrarian questions from transition to globalization. En: A. Akram-Lodhi, \& C. Kay. (Eds.), Peasants and Globalization (pp. 239-261). Londres, Inglaterra: Routledge.

Boltvinik, J., \& Archer-Mann, S. (2016). Peasant poverty and persistence in the Twenty-first century. Theories, debates, realities and policies. Londres, Inglaterra: Comparative Research Programme on Poverty (CROP)-Zed Books. 
Cáceres, D. M. (2004). Lógica práctica, estructura tecnológica y abordaje productivo. Una perspectiva dinámica. Revista Interdisciplinaria de estudios agrarios, 20(1), 5-40.

Chayanov, A. (1974). La organización de la unidad económica campesina. Buenos Aires, Argentina: Nueva Visión.

De Dios, R. (2015). Políticas de tierras, una deuda pendiente en La Argentina. Ponencia presentada en el Congreso de la Asociación Latinoamericana de Sociología (ALAS). Costa Rica.

Diotto, M., Sarandón, S., Lorda, M., \& Flores, C. (2014). Construcción y aplicación de indicadores para evaluar la sustentabilidad en modelos de producción agrícola-ganaderos orgánicos en el área de secano del Partido de Patagones. En C. Albaladejo, R. N. Bustos Cara, \& M. Gliscard. (Eds.). Transformaciones de la actividad agropecuaria de los territorios y de las políticas públicas: entrelazamientos de lógicas (pp. 379-392). Bahía Blanca, Argentina: Editorial de la Universidad del Sur (Ediuns).

Foladori, G., \& Tommasino, H. (2000). El concepto de desarrollo sustentable 30 años después. Cadernos de Desenvolvimento e Meio Ambiente, 1, 41-56. doi: http://dx.doi.org/10.5380/dma.v1i0.3056

Kay, C. (2001). Los paradigmas del desarrollo rural en América Latina. En: F. García Pascual (Coord.). El mundo rural en la era de la globalización: incertidumbres y potencialidades. (pp. 337-430). Madrid, España: Universidad de LleidaMinisterio de Agricultura, Pesca y Alimentación

Khusro, A. M. (1973). The Economics of Farm Size and Land Reform in India. India: Macmillan.

Llambí, L. (1989). Emergence of capitalized family farms in Latin America. Comparative studies in society and history, 31(4), 745-774. doi: https://doi.org/10.1017/S0010417500016182

Long, N., Van der Ploeg, J. D., Curtin, C., \& Box, L. (1986). The commoditization debate: labour process, strategy and social network. Netherlands: Agricultural University Wageningen (UH).

Masera, O., \& Lopez-Riadura, S. (2000). Sustentabilidad y sistemas campesinos: cinco experiencias de evaluación en el México rural. México: Mundiprensa México.

Paz, R. (2008). Mitos y realidades sobre la agricultura familiar en Argentina: reflexiones para su discusión. Problemas del desarrollo, 39(153), 57-82.

Paz, R. G., Rodríguez-Sperat, R., \& González, V. G. (2009). Desarrollo territorial y eficiencia sistémica. El caso de la cuenca lechera caprina de Santiago del Estero (Argentina). Territorios, 20(20), 111-134.

Paz, R., Rodríguez Sperat, R., González, V., \& Lipshitz, H. (2011). Producción económica en una pequeña explotación lechera caprina: hacia un diseño alternativo de desarrollo rural. Revista Asociación Latinoamericana de Producción Animal, (Maracay), 18(3-4), 97-111.

Rodríguez-Sperat, R., Paz, R. G., Suarez, M. V., \& Díaz, J. P. (2015). Construyendo mercados desde la propia finca. Tres experiencias sobre circuitos cortos en la agricultura familiar. Agro Sur, 43(1), 3-17. doi: http://dx.doi.org/10.4206/agrosur.2015.v43n1-02

Rodríguez-Sperat, R., \& Jara, C. E. (2018). Eficiencia y agricultura familiar: más de un siglo de debate sin suficientes respuestas. Agricultura, Sociedad y Desarrollo, 596-617 doi: https://doi.org/10.22231/asyd.v15i4.902

Sarandón, S. J., Zuluaga, M. S., Cieza, R., Gómez, C, Janjetic, L., \& Negrete, E. (2006). Evaluación de la sustentabilidad de sistemas agrícolas de fincas en misiones, argentina, mediante el uso de indicadores. Agroecología, 1, 19-28.

Sarandón, S. J., \& Flores, C. C. (2009). Evaluación de la sustentabilidad en agroecosistemas: una propuesta metodológica. Agroecología, 4, 19-28.

Sarandón, S. J., \& Flores, C. C. (2014). Agroecología: bases teóricas para el diseño y manejo de agroecosistemas sustentables. Buenos Aires, Argentina: Editorial de la Universidad de La Plata.

Schejtman, A. (1980), 'Economía campesina: lógica interna, articulación y persistencia', Revista de la CEPAL, 11, pp. 121-140.

Schneider, S. (2003). A pluriatividade na agricultura familiar. SciELO-Editora da UFRGS 
Sevilla-Guzmán, E. (2011). Sobre los Orígenes de la agroecología en el pensamiento marxista y libertario. La Paz, Bolivia: AGRUCO-Plural Editores- Centre for development and evironment (CDE)- Nacional Centre of competence in research (NCCR).

Shanin, T. (1973). The nature and change of peasant economies. Sociología Ruralis, 13(2), 139-171. doi: https://doi.org/10.1111/j.1467-9523.1973.tb00884.x

Smith, G. (1986). "Reflections on the social Relations of Simple Commodity Production”. Journal of Peasant Studies, 15 (4), 500 529.

Toledo, V. M. (2002). Agroecología, sustentabilidad y reforma agraria: la superioridad de la pequeña producción familiar. Agroecologia e Desenvolvimento Rural Sustentável, 3(2), 27-36.

Tommasino, H. (2006). Sustentabilidad e indicadores: indicadores socioeconómicos en la producción lechera familiar. En: H. Tommasino, \& P. Hegedüs. (Eds.). Extensión; reflexiones para la intervención en el medio rural (pp. 101-120). Montevideo, Uruguay: Departamento de publicaciones de la Facultad de Agronomía, Universidad de la República Oriental de Uruguay.

Van der Ploeg, J. D. (2015). El campesinado y el arte de la agricultura. Un manifiesto chayanoviano. Distrito Federal, México: Miguel Ángel Porrúa.

Van der Ploeg, J. D. (2010). Nuevos Campesinos. Campesinos e imperios alimentarios. Barcelona, España: Icaria.

Van der Ploeg, J. D. (2006). 0 modo de produção camponês revisitado. En: S. Schneider. (Ed.). A diversidade da agricultura familiar. Porto Alegre, Brasil: UFRGS. 